\title{
WATER QUALITY IMPROVEMENT USING RENEWABLE ENERGIES
}

CATALINA RALUCA MOCANU, Lecturer, PhD, University Politehnica of Bucharest, Power Engineering Faculty, Romania, e-mail mocanu_catalinaraluca@yahoo.co.uk

LIVIU VALENTIN BALANESCU, Lecturer, PhD, Police Academy "Alexandru Ioan Cuza", Fire Officers Faculty, Romania, e-mail liviubalanescu@yahoo.com

\begin{abstract}
To reduce the negative effects of eutrophication processes in water bodies it is necessary to improve water quality by ensuring the necessary oxygen concentration. The paper proposes a new innovative solution for the improvement of lake water quality. The premises for the implementation of the experimental floating platform which will aerate the lake waters will be presented. To give a specific view over the oxygen dispersion into the lake, numerical simulations in CFD software will be presented in different cases.

The protection of drinking water resources against pollution is a common task of outstanding importance for the water management and environment protection sectors. To prevent water supply problems arising from the short and medium-term quality deterioration of resources caused by pollution incidents, it is vital to develop methods for monitoring the quality of resources as well as methods for monitoring and predicting serious pollution events to protect water users. In the case of vulnerable drinking water resources, the establishment and maintenance of an early warning monitoring system is important. Emergency treatment technologies are also needed by the waterworks to treat the water for periods when the quality of the water has temporarily deteriorated. Innovative solutions for the improvement of water quality consist in using a floating platform equipped with aeration systems. The equipment used to aerate the lake waters is powered by the area renewable energy (solar, wind). So, this platform can be used in isolated area, where there is no energy supply from the national network.
\end{abstract}

Keywords: Aeration, renewable energies, numerical simulation.

\section{Introduction}

Quantification of pollution is necessary for environment quality evaluation and elaboration of a successful strategy for water quality improvement. Reduction of threats resulting from pollution is always the first step to implement ecological measures. Development of agriculture, industry and urbanization will result in increasing water use, generate more pollutants from both municipal and industrial uses of water, and contribute to the decline of water resources quality. This may result in the limitation of water resources used by people living along water bodies.

Emergency treatment technologies are also needed by the waterworks to treat the water for periods when the quality of the water has temporarily deteriorated. Innovative solutions for the improvement of water quality consist in using a floating platform equipped with aeration systems.

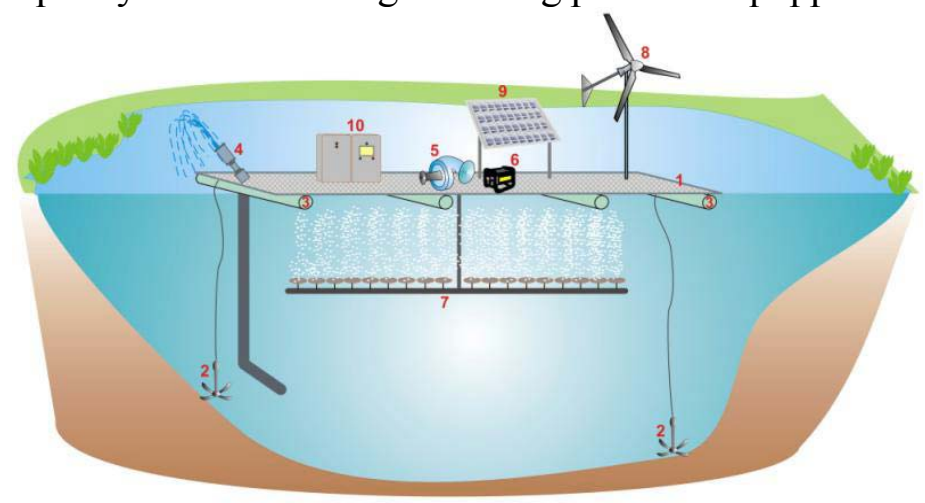

Fig. 1 - Floating platform 
The equipment used to aerate the lake waters is powered by the area renewable energy (solar, wind). So, this platform can be used in isolated area, where there is no energy supply from the national network.

The floating platform (figure 1) is composed of the floating platform (1), the anchorage system (2), the floating system (3), the suction pump (4), the blower (5), the generator (6), the aeration system (7), the micro wind turbine (8), the photovoltaic panel (9), the command and data transmission panel (10). Because this floating platform will be installed at 500 meters from the shore it must be energetically autonomous. To ensure the energetic needs of the platform equipment it will be necessary to build photovoltaic panels and a wind micro-turbine, so that the renewable energy of the area should be used. This equipment will be connected to the floating platform automation system. The automation system will be capable to transmit the collected data (dissolve oxygen concentration, energy consume) to a distance operator.

In the paper, different cases of platform location in the lake will be numerically simulated in FlexPDE software.

\section{Mathematical and numerical simulation}

The purpose of mathematical modeling and numerical simulation is to identify the best position of the aeration equipment to have the optimum oxygen concentration in the lake. The aeration process depends on the lake flow regime. The air is dispersed into the water using pneumatic equipment put on the bottom of the floating platform and connected to a blower. The mathematical model is based on the dispersion equation of dissolved oxygen in water $[1,2]$, considering complete mixing in the lake, due to aeration motion:

$$
\frac{d C}{d t}+u \frac{d C}{d x}+w \frac{d C}{d y}=\varepsilon_{x} \frac{d C}{d x}+\varepsilon_{y} \frac{d C}{d y}-k^{*} C^{2}
$$

Where, $C$ is oxygen concentration, $u$ is the horizontal water velocity, $(\mathrm{u}=0.5 \mathrm{~m} / \mathrm{s}), w$ is the lift velocity because of gas bubbles (gas bubbles flow along Oy - from now on standing for the vertical axis instead of $\mathrm{Oz}),(\mathrm{w}=1 \mathrm{~m} / \mathrm{s}), \varepsilon_{x}$ is the axial dispersion coefficient, $\left(\varepsilon_{\mathrm{x}}=0.09 \mathrm{~m}^{2} / \mathrm{s}\right), \varepsilon_{y}$ is the vertical dispersion coefficient, $\left(\varepsilon_{\mathrm{y}}=5 \mathrm{~m}^{2} / \mathrm{s}\right), k$ is the oxygen consumption factor $(\mathrm{k}=0.2)$.

The equation (1) will be simulated in different conditions as shown in figures 2 to 12 .

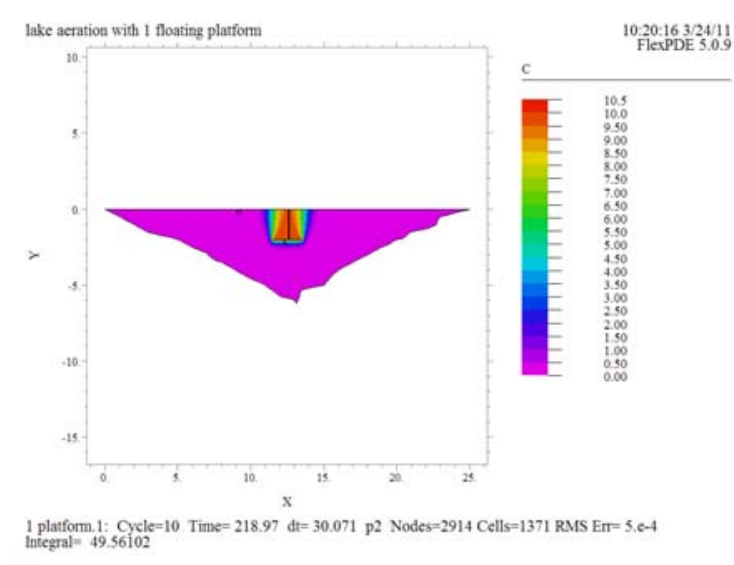

a)

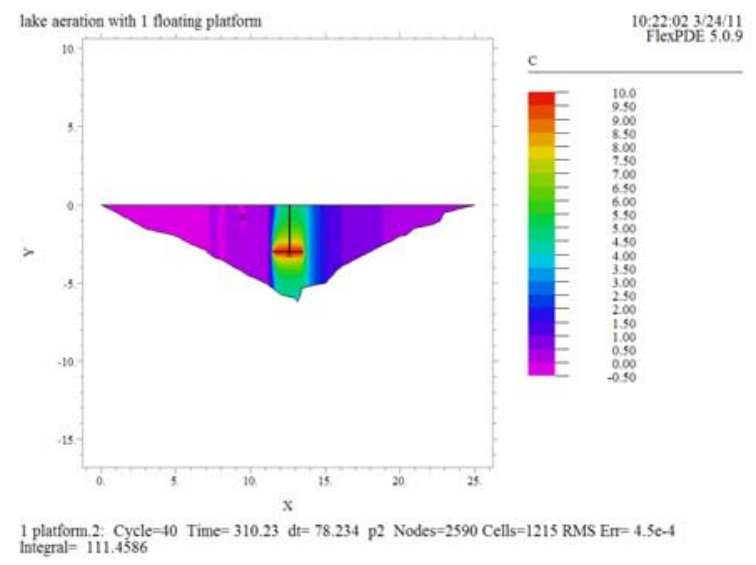

b)

Fig. 2 - Dissolved Oxygen concentration profiles at different placement of the aeration system into the lake, 1 aeration system is used

In figure 2.a an oxygen consumption factor was introduced, $k^{*} C^{2}$. One can observe in figure 2.b the influence of the aeration system if this is placed deeper into the lake. The oxygen mass introduced into the lake influences a larger zone. 
In figures $3 \mathrm{a}, 3 \mathrm{~b}$ and $3 \mathrm{c}$ the dissolved oxygen concentration evolution along the line 1-2 into the lake transversal section in 3 different cases are shown. The higher value of the dissolved oxygen concentration is in the $3 . \mathrm{b}$ case where there is no consumption factor. This is not according to reality.

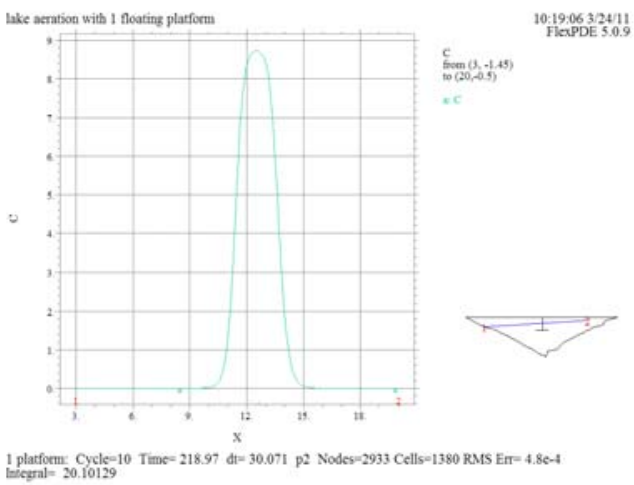

a)

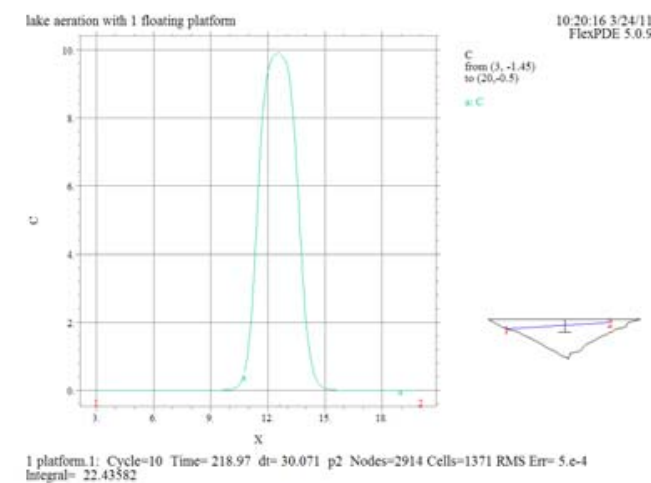

b)

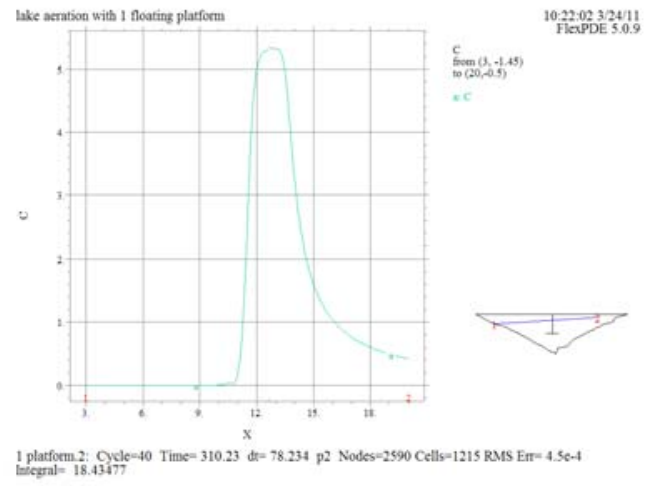

c)

Fig. 3 - Evolution of Dissolved Oxygen Concentration in the lake transversal section

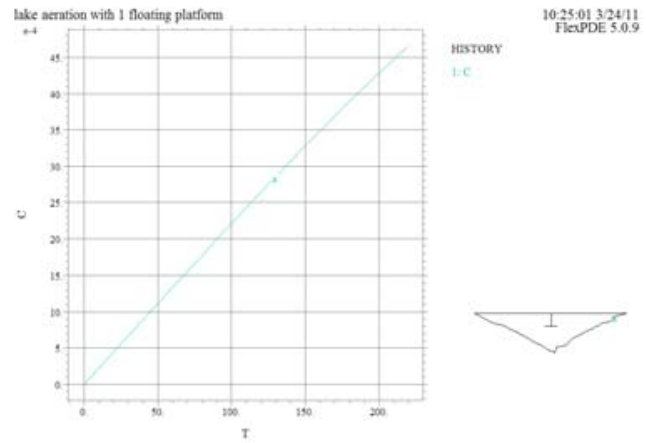

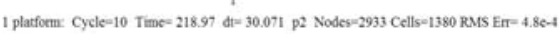

a)

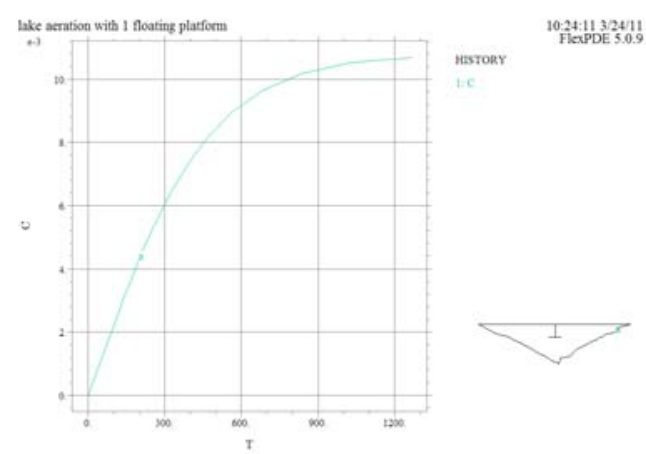

1 plafform th: Cycle-20 Time 1264.2 dto 300.71 p2 Nodes -2933 Cellss=1380 RMS Er $-4.8 \mathrm{e}-1$

b)

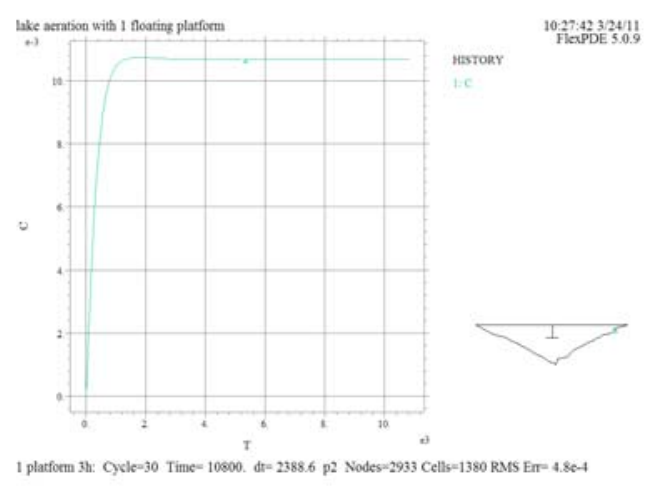

c)

Fig . 4 - Evolution of Dissolved Oxygen Concentration, same simulation conditions for aeration time. 1 aeration systems is used. a) 10 minutes, b) 1 hour, c) 3 hours 
Form figures 4 a), b) and c) one can observe that the longer the aeration system works the higher the dissolved oxygen concentration into the lake.

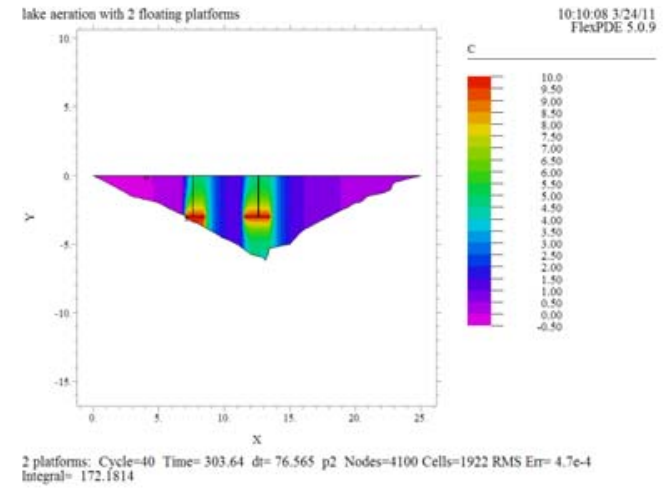

a)

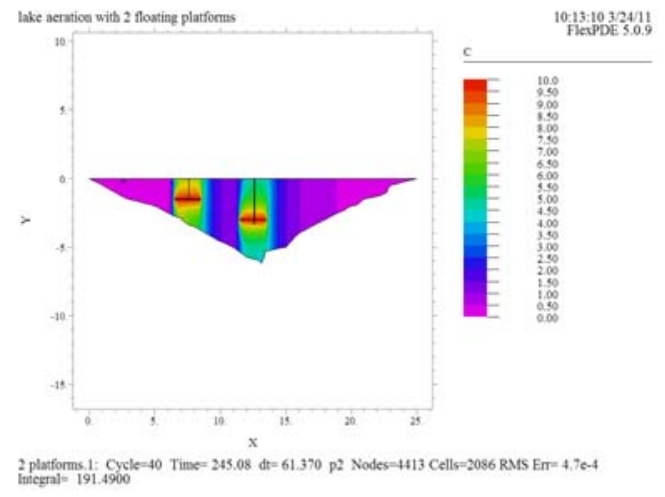

b)

Fig. 5 - Dissolved Oxygen concentration profiles into lake domain. 2 aeration systems are used.

In figures 5.a and 5.b two aeration systems placed into the lake domain are shown. The difference between them is the placement of the aeration systems. In figure 5.a they are placed at the same depth. Because the dissolved oxygen concentration dispersion into the domain was unsatisfied the aeration system placed near the shore was placed at a smaller depth so that the dissolved oxygen concentration has a desired evolution.
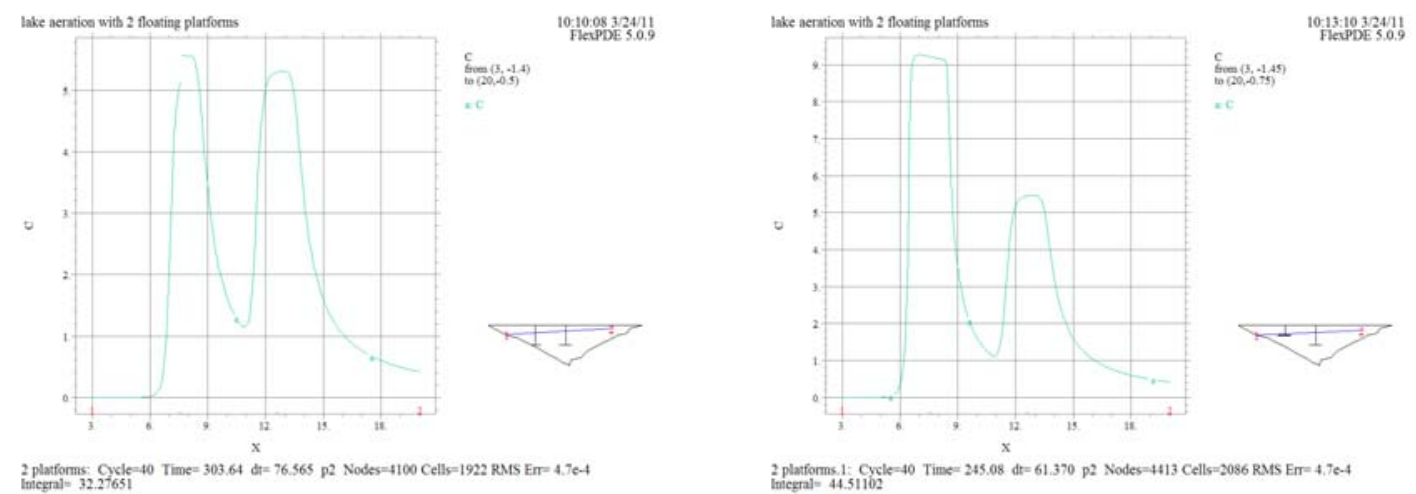

Fig. 6 - Evolution of Dissolved Oxygen Concentration in the lake transversal section

In figures 6.a and 6.b one can observe that the placement of the aeration systems influenced directly the dissolved oxygen concentration into the lake. In this case it is preferable to use different placement for the aeration systems so the sediment layer do not be disturbed. In figures 7.a, b, c the influence of aeration systems will be simulated for different work time over the lake regime. One can observe that the longer the aeration systems work the value of the dissolved oxygen concentration into the water lake remains in the same parameters. For this reason it is necessary to install dissolved oxygen sensors in order to evaluate the correct values into the lake, and to stop the aeration equipment. In this way the energy is conserved for further uses.

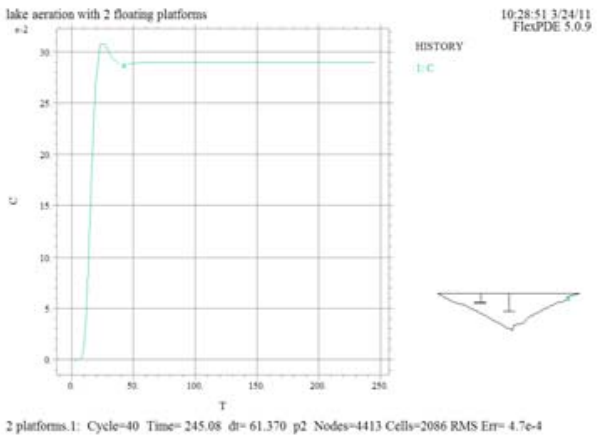

a)

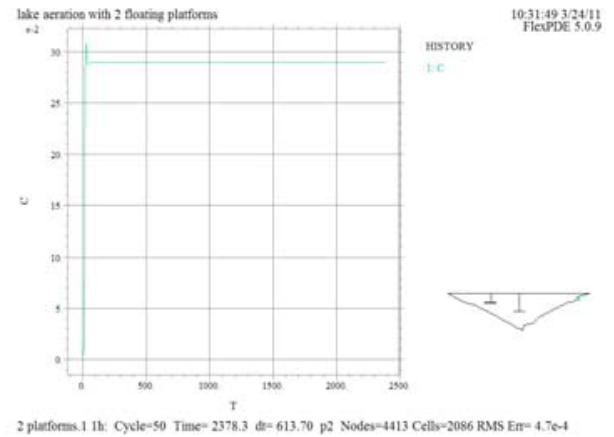

b) 


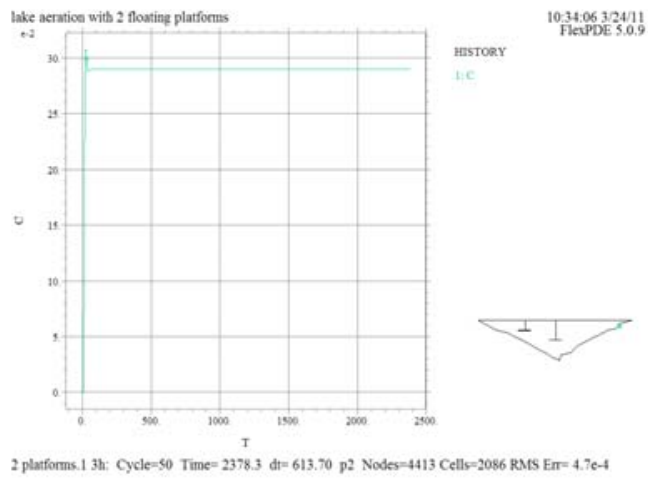

c)

Fig. 7 - Evolution of Dissolved Oxygen Concentration, same simulation conditions for aeration time. 2 aeration systems are used. a) 10 minutes, b) 1 hour, c) 3 hours

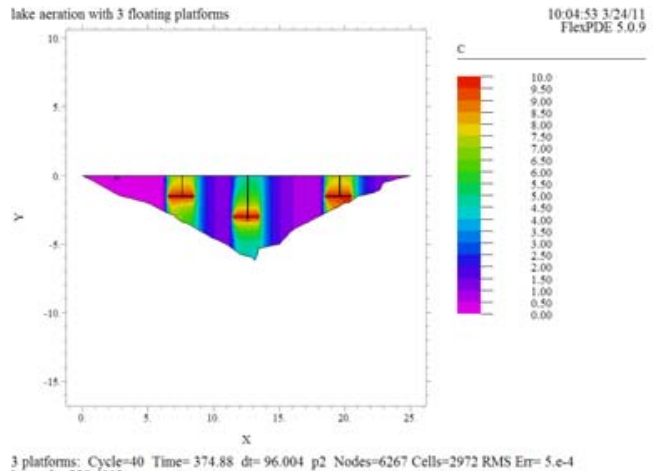

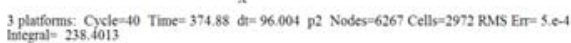

Fig. 8 - Dissolved Oxygen concentration profiles into lake domain. 3 aeration systems are used.

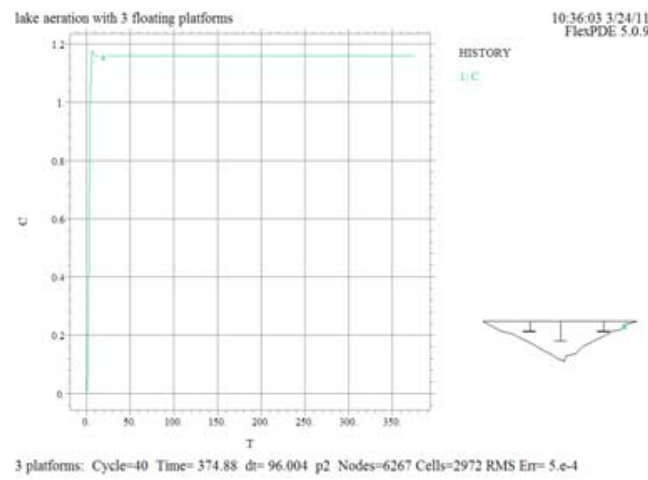

a)

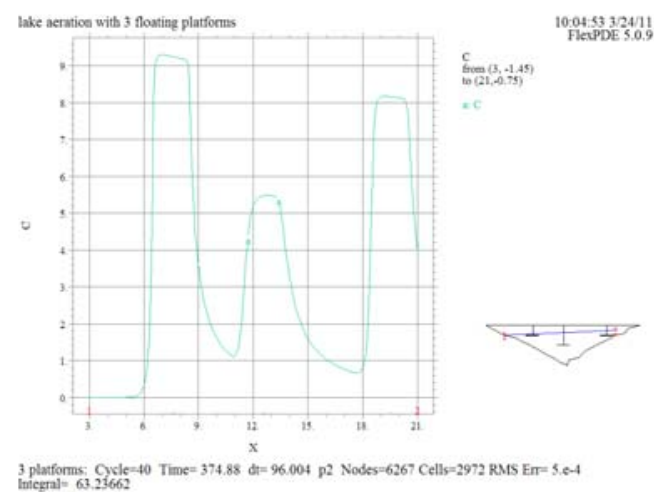

Fig. 9 - Dissolved Oxygen concentration evolution in the lake transversal section

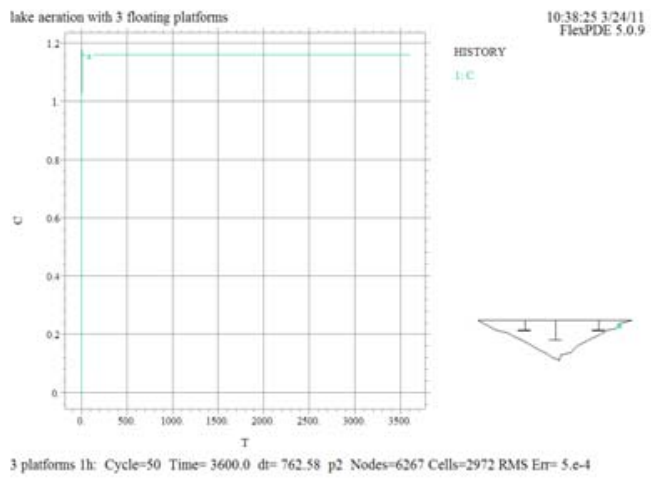

b)

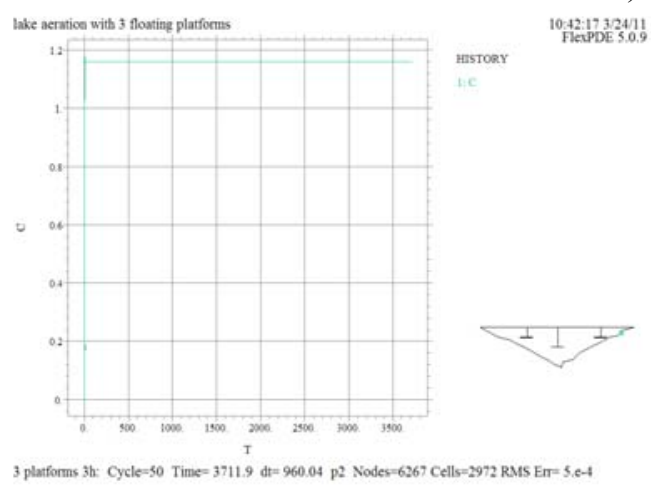

c)

Fig. 10 - Evolution of Dissolved Oxygen Concentration, same simulation conditions for aeration time. 3 aeration systems are used. a) 10 minutes, b) 1 hour, c) 3 hours 
From figures 10 one can observe that the longer for the aeration systems work the value of the dissolved oxygen concentration into the water lake remains in the same parametrs. The difference between the uses of 2 or 3 aeration equipments it is strongly observed. The values for the dissolved oxygen concentration into the lake when 3 aeation systems are used reach the maximum value after 10 minutes. For this reason it is necessary to evaluate if it is more economical to use more aeration systems or to use less aeartion systems for a longer time.

\section{Conclusions}

The results of theoretical researches (mathematical modeling and numerical simulation with FlexPDE software) realized for the lake water aeration with a floating platform show that the application of this method increases the dissolved oxygen concentration into the lake with major implication in the decrease of the eutrophication processes during the summer seasons. The solution proposed by the authors is an innovative one because of the renewable energy use of the area for the supply of the necessary energy for the mechanical equipment used for air injection. The numerical simulation shows that the influence of the aeration system in the lake depends on its location into the water (close to shore or not; at different depths), and the number of the aeration systems and the aeration time.

\section{References}

[1]. Robescu, D., Mocanu C.R., (2006). Oxygen dispersion modelling in the water transport pipes, Scientific Bulletin, Series D - Mechanical engineering, Vol 68(1), pp. $35-42$.

[2]. Mocanu, C.R., Balanescu,L.V., Robescu D., Robescu, D. (2010). Wastewater pretreatment processes numerical simulations in the sewage system, European Science Foundation Global Change Research II: Environmental Crisis, Energy Issues and Global Regulation Policies, Porquerolles Island, France. 